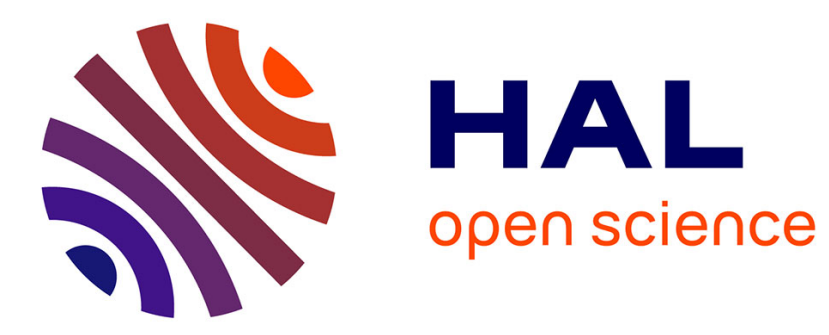

\title{
Large Surface X-Ray Pixel Detector
}

P. Delpierre, J-F. Berar, L. Blanquart, N. Boudet, P. Breugnon, B. Caillot, J-C. Clemens, C. Mouget, R. Potheau, I. Valin

\section{To cite this version:}

P. Delpierre, J-F. Berar, L. Blanquart, N. Boudet, P. Breugnon, et al.. Large Surface X-Ray Pixel Detector. 2001 IEEE Nuclear Science Symposium (NSS) and Medical Imaging Conference (MIC), Nov 2001, San Diego, United States. N23.2-4 p. in2p3-00012293

\section{HAL Id: in2p3-00012293 https://hal.in2p3.fr/in2p3-00012293}

Submitted on 30 Jul 2002

HAL is a multi-disciplinary open access archive for the deposit and dissemination of scientific research documents, whether they are published or not. The documents may come from teaching and research institutions in France or abroad, or from public or private research centers.
L'archive ouverte pluridisciplinaire HAL, est destinée au dépôt et à la diffusion de documents scientifiques de niveau recherche, publiés ou non, émanant des établissements d'enseignement et de recherche français ou étrangers, des laboratoires publics ou privés. 


\title{
Large Surface X-Ray Pixel Detector
}

\author{
P. Delpierre, J.F. Berar, L. Blanquart, N. Boudet, P. Breugnon, \\ B. Caillot, J.C. Clemens, C. Mouget, R. Potheau, I.Valin
}

\begin{abstract}
A large surface semi-conductor photon counting pixel detector is being built. As a first step, this detector is optimized for $X$-ray crystallography. The aim is to provide a high dynamic range $\left(>10^{9}\right)$, high counting rate $\left(10^{7} \mathrm{ph} / \mathrm{s}\right.$ per pixel) and fast image readout $(3 \mathrm{~ms})$. A full custom chip has been produced and tested, and results will be presented. Prototypes of $6 \mathrm{~cm}^{2}$ with pixels of $330 \mu \mathrm{m} \times 330 \mu \mathrm{m}$ have been built together with a full fast readout system. These prototypes have been tested in the D2am beam line at the ESRF synchrotron (Grenoble, France), for different photon energies (10 to $24 \mathrm{KeV})$. The signal is well out of the noise until $10 \mathrm{KeV}$. We will give results on the efficiency as a function of the photon rate and the effect of the threshold on the efficiency between the pixels. Furthermore, to demonstrate the large dynamic range, we made diffraction images. We will then describe the $6.4 \mathrm{~cm} \times 6.4 \mathrm{~cm}$ camera that we are building and our future plans.
\end{abstract}

\section{INTRODUCTION}

Dhoton counting pixel detectors are being investigated as P a solution to improve CCD's regarding the dynamic range, the image readout duration, and to suppress the noise with an adjustable threshold. However, photon counting is limited in rate while CCD's are not. A full custom chip has been built with special efforts to push the counting rate as high as possible. Part of our group has a long experience to build large surface pixel detectors for High Energy Physics experiments [1,2]. We plane to use the same technique to build large surface X-ray detectors ( $6 \mathrm{~cm}$ x $6 \mathrm{~cm}$ or more). To start with, we have build $4 \mathrm{~cm} \times 1.6 \mathrm{~cm}$ prototypes. They have beam tested in an X-ray beam and results will be reported. We will also describe the detector that we are building for the D2AM beam line of the ESRF synchrotron (Grenoble, France).

Manuscrpt received in November 7, 2001

P. Delpierre, P. Breugnon, J.C. Clemens, R. Potheau and I. Valin are with the CPPM/IN2P3/CNRS, 163 Av. de Luminy, case 907, F-13288 Marseille Cedex 9, France (telephone: +33 4918272 00, e-mail: delpierre@cppm.in2p3.fr).

J. F. Berar, N. Boudet, B. Caillot and C. Mouget are with the Laboratoire de Cristallographie/CNRS, BP 166, F-38042 Grenoble Cedex 09, France, (telephone: +334768874 14, e-mail: berar@esrf.fr).

L. Blanquart is with the Lawrence Berkeley National Laboratory, MS 50-256, 1 Cyclotron road, Berkeley, CA94720, USA (telephone: +1-510486.66.23, e-mail: blanquart@lbl.gov).

\section{THE CHALLENGE}

The aim is to build a crystallographer without the limitations of the current CCD based detectors, that is:

- needs low temperature to reduce the noise (the noise is integrated during the readout)

- $\quad$ the dynamics is limited to about 14-bit $\left(1.610^{4}\right)$

- for the x-ray detection a light converter is mandatory

- a fast shutter is needed to control the data taking time

With pixel detector the challenge is the following:

- $\quad$ sensitivity : $1 \mathrm{ph} /$ pixel (needed to see satellite peaks)

- $\quad$ noise $:<1$ ph /hour per pixels

- dynamic range $>10^{9}$ (32-bit counters)

- electronic control of data taking time at a few $100 \mathrm{~ns}$

- counting rate from $10^{-2}$ to $10^{7}$ photons/second/pixel

- dimensions : $8 \mathrm{~cm}$ x $8 \mathrm{~cm}$

- $\quad$ real time study : $<3 \mathrm{~ms} /$ frame, 128 frames local memory

- $\quad$ thickness $<1 \mathrm{~mm}$ (equivalent silicon)

\section{FIRST PROTOTYPES}

To study the feasibility of an x-rays pixel detector, we have built prototypes. A pixel detector includes a sensor substrate segmented in pixels on which electronic chips are bump-bonded. For each pixel, the electronic chip includes one analog cell followed by a discriminator, and readout logic.

For the first prototypes we have used existing sensors from a physics experiment [1] (DELPHI, CERN, Geneva). The pixel size is $330 \mu \mathrm{m} \times 330 \mu \mathrm{m}$, which is close to the usual Xray sources. The size is $4 \mathrm{~cm} \times 1.6 \mathrm{~cm}$.

We had to build dedicated electronic chips, since the ones from physics experiments are optimized for selective readout and not for photon counting. This chip [3] (the XPAD) has been designed to satisfy the characteristics described above. It has been done in the standard technology AMS $0.8 \mu \mathrm{m}$ ("Austria Mikro System"). Special care was taken to reach a high counting rate. The threshold can be adjusted pixel by pixel. The pixels can be disabled individually. Each pixel includes a 16-bit counter which can be read during the exposure.

Ten chips have been bump-bonded (by Tronics, Grenoble) on each of 8 sensors. One of them is shown on the Fig.1. These pixel modules have been glued on printed circuit boards for tests. 
An external readout and memory board has been build. This board includes an Altera programmable chip and memories for 128 images of 32-bit per pixel. During the exposure the system scans (at $33 \mathrm{MHz}$ ) the pixels 16-bit counters overflows and add them to the corresponding 16-bit counter in the readout and memory board. At the end of exposure the full contains of the pixel counters are read and add as lower significant bits. The total readout time is $3 \mathrm{~ms}$ and it can be reduced if necessary.

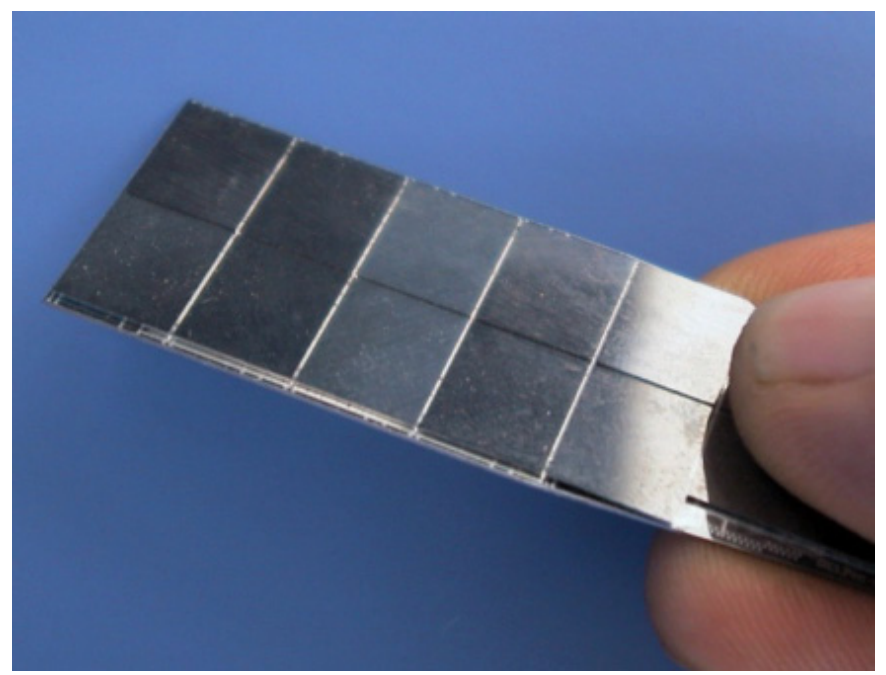

Fig. 1. Pixel module, 10 XPAD chips are bump-bonded on a silicon sensor.

\section{ELECTRONIC CHIP TEST RESULTS}

The electronic chip has been tested before to be mounted on the sensor. The noise is $200 \mathrm{e}^{-} \mathrm{RMS}$. The maximum rate

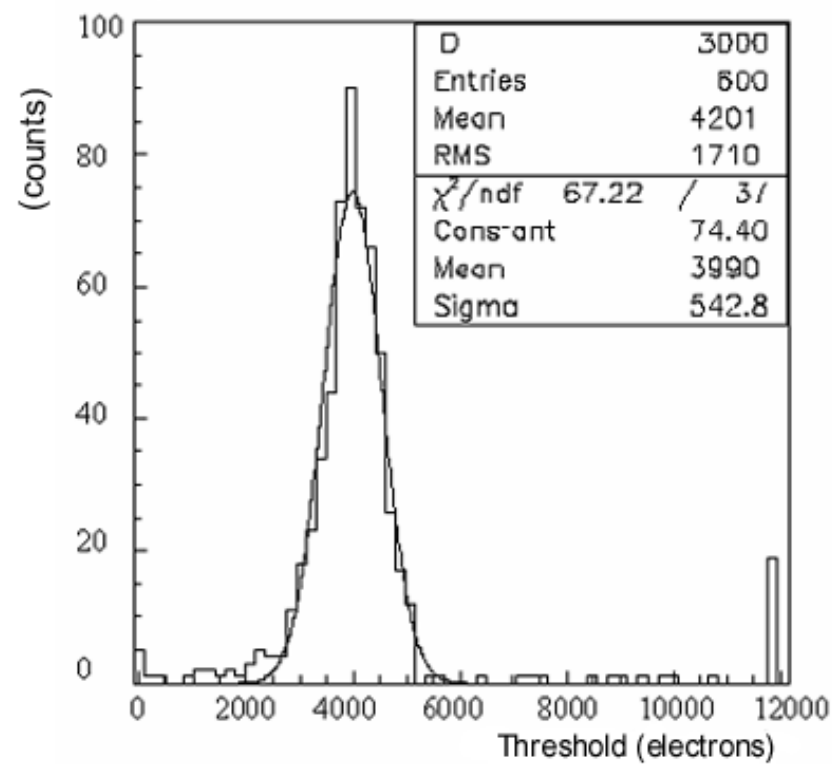

Fig. 2. Threshold distribution for one chip (600 pixels) has been measured by the mean of the analog test input. The pulse width is 50 ns FWHM, then, in recurrent mode, a rate of $10^{7} \mathrm{pulses} / \mathrm{second}$ was easily reached.

After mounting on the sensor, the input capacitance is much higher (about $800 \mathrm{fF}$ ) and the measured noise is $350 \mathrm{e}^{-}$. To be able to work at very low threshold, the two other important parameters are the crosstalk and the threshold spread. The crosstalk was measured and it is $0.4 \%$, which is pretty good. The threshold spread is $540 \mathrm{e}^{-}$. This is large but acceptable. However there is a tail of out of range pixels, as it can be seen in the threshold distribution on the Fig.2. This is a defect that we understand now and it will be corrected in the next version of electronic chip. For the following tests, these pixels have been disabled.

\section{PRototyPe TEST RESUlTS}

The modules have been tested in the ESRF-D2AM beam line. From threshold curves we could calibrate the detector as a function of the $\mathrm{x}$-ray energy. The derivative of the threshold curves are shown in the Fig.3. The signal is well separated from the noise until $10 \mathrm{keV}$. The energy resolution is $1 \mathrm{MeV}$.

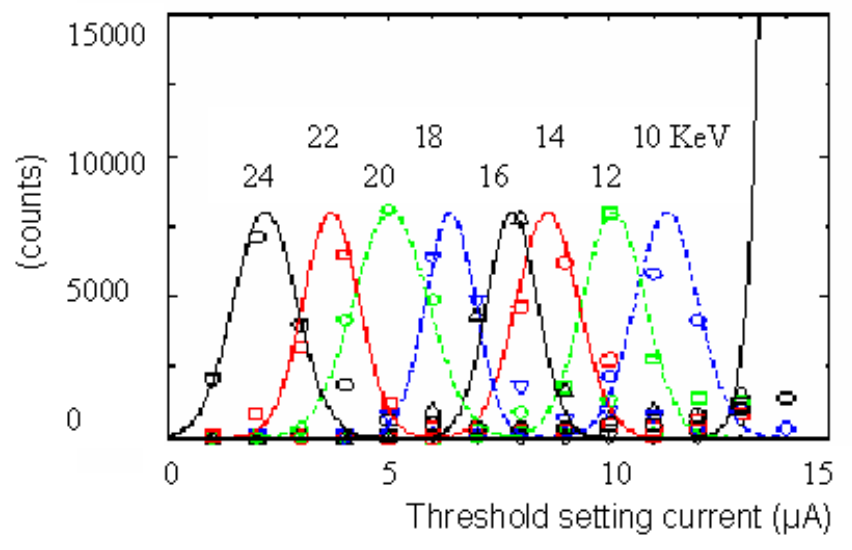

Fig. 3. Energy calibration, the resolution is about $1 \mathrm{MeV}$.

One important measurement for photon counting pixel detectors is the efficiency between the pixels. If the threshold is too high, we lose photons because the charges are shared between the pixels and the part on each one can be lower than the threshold. If the threshold is too low, the charges can be above the threshold for both pixels and we have a double counting.

This measurement has been done on several pixels and the results are in the Fig.4. For this measurement the beam has been tuned to $10 \mu \mathrm{m}$. As one can expect, the correct setting of the threshold corresponds to the half of the charges deposited by the photon. For a beam of $25 \mathrm{keV}$, the charge from the photon conversion is around 7000 electrons and one can see that with a threshold of 3500 electrons the distribution becomes uniform. 
(counts)

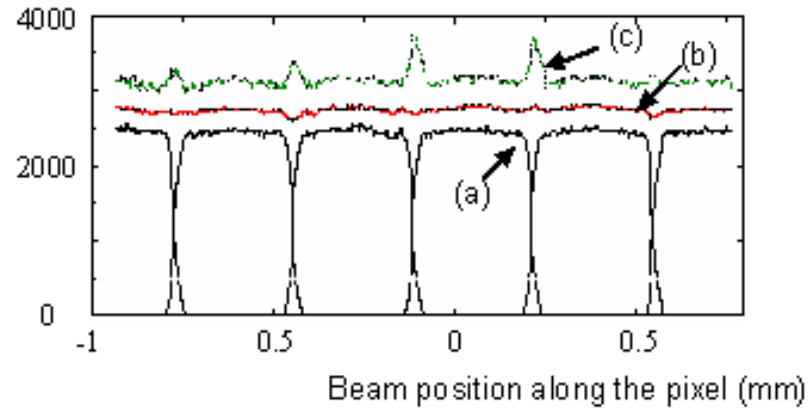

Fig. 4. Counting efficiency for a $10 \mu \mathrm{m}$ beam scan along the pixels.

(a) Counting per pixels, threshold $=3500 \mathrm{e}^{-}$

(b) Total counting, threshold $=3500 \mathrm{e}^{-}$

(c) Total counting, threshold $=3200 \mathrm{e}$

The counting rate was measured in the $2 / 3$ filling mode of the ESRF beam. That means that the real counting rate is 1.5 times higher than measured. The result is in the Fig 5. It is linear until $10^{5} \mathrm{ph} / \mathrm{s}$ per pixel and the maximum measured rate is around $1 \times 10^{6} \mathrm{ph} / \mathrm{s}$ per pixel. Then the maximum real counting rate is $1.5 \times 10^{6} \mathrm{ph} / \mathrm{s}$ per pixel. The noise is less than one count per hour per pixel and we can measure rates as low as $0.01 \mathrm{ph} / \mathrm{s}$ per pixel. Also on Fig. 5, on can see that the neighboring pixel which receives few photons from the beam halo, is not disturbed by the large charge on its neighbor while it would have been with the CDD by "blooming effect".

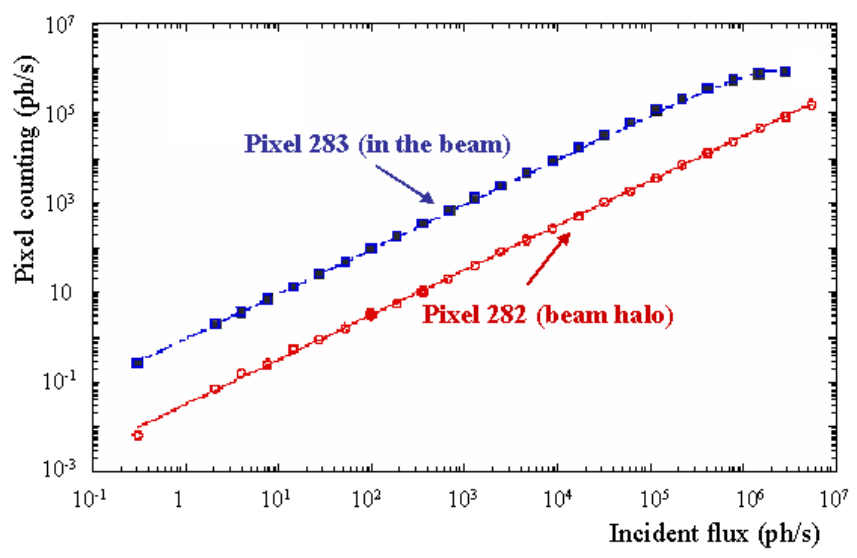

Fig. 5. Counting rate linearity. The beam duty cycle is $2 / 3$, and then the real rate is 1.5 times more.

To have a first idea of the behavior of pixel detectors in a real X-ray experiment the detector was mounted on a SAX (Small Angle X-ray scattering) table.

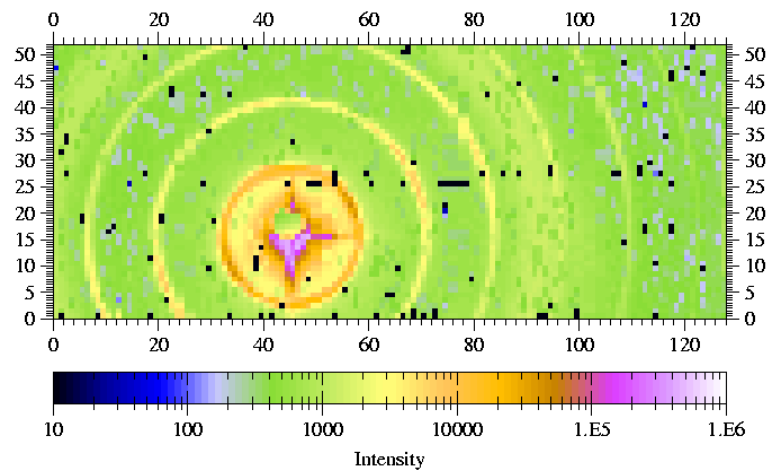

Fig.6. Diffraction image from a $20 \mathrm{keV}$ X-ray beam on a silver behenate sample. The shadow between the $3 \mathrm{rd}$ and the 4 th ring is due to the diffusion on the module cover. The dark points are disabled pixels (threshold out of range).

A silver behenate sample was installed and exposed during 400 seconds with a thin $20 \mathrm{keV}$ Xray beam. The resulting image is represented in the Fig.6. We can measure up to 7 order of diffraction with a dynamic in intensity of 5 orders of magnitude.

However, on this picture, one can see black spots. This corresponds to the pixels with threshold out of range which have been disabled, as it was explained above (see the paragraph IV). The shadow between the $3^{\text {rd }}$ and the $4^{\text {th }}$ rings is due to the diffusion on the plastic cover which protects the detector.

\section{NEW PROTOTYPES}

To correct the threshold spread a new pixel chip (XPAD2) has been designed. It has already been submitted in AMS. $(0.8 \mu \mathrm{m})$. The defect in the analog cell has been corrected and the threshold tuning range has been enlarged.

We have also designed sensors adapted to this application. The pixel contact pads are much smaller $(60 \mu \mathrm{m}$ of diameter instead of $140 \mu \mathrm{m}$ for the DELPHI sensors). That will reduce the input capacitance and then the noise. That will also reduce the pulse width so that the maximum counting rate will be increased.

The sensor wafers (4") include two sizes of chips. One is similar to the first prototypes $(4 \mathrm{~cm} \times 1.6 \mathrm{~cm})$ the other is 6.4 $\mathrm{cm} \times 0.8 \mathrm{~cm}$. These last chips will serve to build a $6.4 \mathrm{~cm} \mathrm{x}$ $6.4 \mathrm{~cm}$ detector plate. They will be glued and wire bonded on thin ceramics boards for the rooting of the signals to the connectors for readout and memory boards. These detector modules will be mounted on an air cooled mechanical support (see the Fig. 7). Readout and memory boards based on the prototype that we have used for the tests will be built and mounted on each tile. The tiles will be linked by a flexible cable to a PC interface board. 


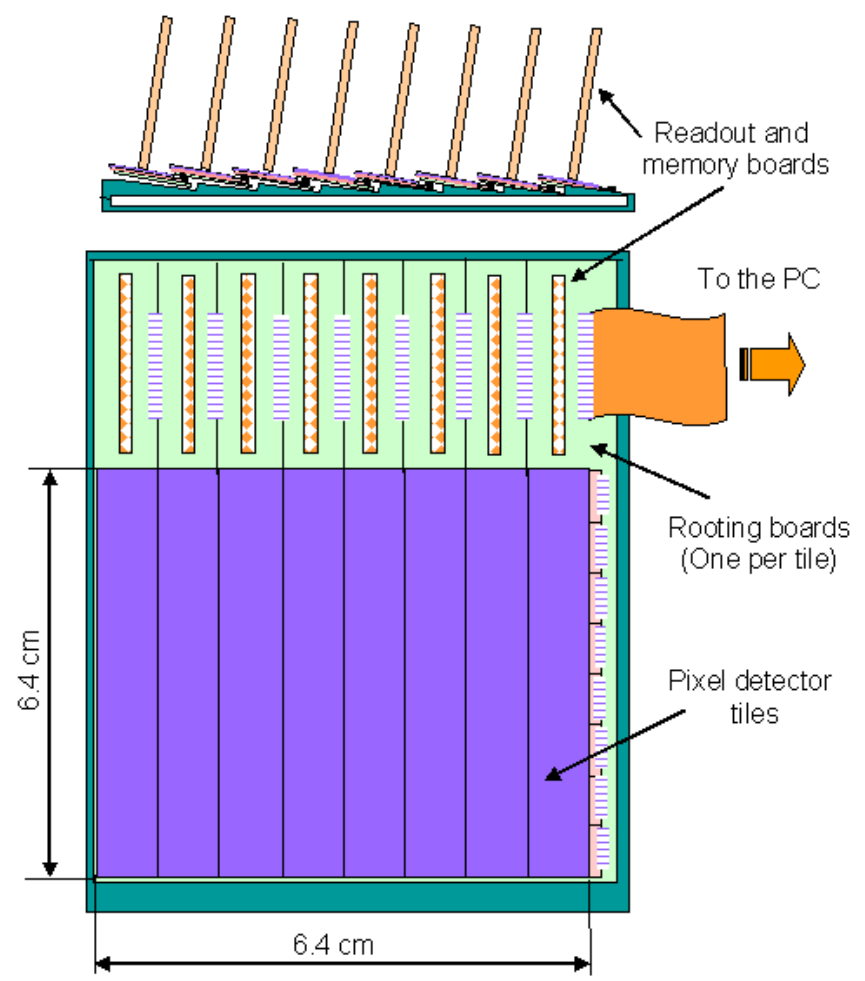

Fig.7. Complete pixel crystallographer prototype.

\section{PERSPeCtIVES}

We plan to build a radiation hard chip in Deep Sub Micronics technology, starting early next year. We will use the same schematic but the pixel size will be around $150 \mu \mathrm{m}$ $\mathrm{x} 150 \mu \mathrm{m}$. These chips will be assembled on radiation hard silicon sensors close to the design of the ATLAS experiment pixel sensors [4]. They will be sized to build a radiation hard $8 \mathrm{~cm}$ x $8 \mathrm{~cm}$ crystallographer.

We are also studying the use of the photon counting pixel detectors for the imaging of small animals. The idea is to associate X-ray radiography to a micro-PET (Positron Emission Tomography) in order to locate the surgical intervention tool with respect to the activated object.

\section{REFERENCES}

[1] K.H. Becks, P.Borghi, J.M. Brunet, M. Caccia, J.C. Clemens, M. Cohen-Solal, et al.., "The DELPHI PIXELS," Nucl. Instr. Meth., vol. A386, pp. 11-17, 1997.

[2] ATLAS pixel detector technical design report, CERN, Geneve.

[3] L. Blanquart, I. Valin, C. Trouilleau, S. Meillere and L. Crest, "XPAd, a New Read-out Pixel Chip for X-ray Counting," presented at the 2000 IEEE Nuclear Science Symposium, Lyon, France.

[4] ATLAS pixel sensors, to be published in Nucl. Instr. Meth. 